\title{
A remote sensing-based approach to estimating montado canopy density using the FCD model: a contribution to identifying HNV farmlands in southern Portugal.
}

\author{
Sérgio Godinho • Artur Gil • Nuno Guiomar • Nuno Neves • Teresa Pinto-Correia
}

\section{Keywords}

Canopy density . FCD. Agroforestry . Montado . Dehesa . Advanced vegetation index

\begin{abstract}
Mapping the land-cover pattern dominated by complex Mediterranean silvo-pastoral systems with an accuracy that enables precise monitoring of changing tree-cover density is still an open challenge. The main goal of this paper is to demonstrate the implementation and effectiveness of the Forest Canopy Density (FCD) model in producing a remote sensing-based and detailed map of montado canopy density over a large territory in southern Portugal. This map will make a fundamental contribution to accurately identifying and assessing High Nature Value farmland in montado areas. The results reveal that the FCD model is an effective approach to estimating the density classes of montado canopy (overall accuracy $=78.0 \%$, kappa value $=0.71$ ). The study alsoshows that the FCD approach generated good user's and producer's accuracies for the three montado canopy-density classes. Globally, the results obtained show that biophysical indices such as the advanced vegetation index, the bare soil index, the shadow index and the thermal index are suitable for estimating and mapping montado canopy-density classes. These results constitute the first remote sensing-based product for mapping montado canopy density that has been developed using the FCD model. This research clearly demonstrates that this approach can be used in the context of Mediterranean agro-forestry systems.
\end{abstract}

Agroforest Syst

DOI 10.1007/s10457-014-9769-3 